\title{
INFÂNCIAS, EDUCAÇÃO E RESISTÊNCIA: PENSANDO OS CORPOS INFANTIS E SUAS MULTIPLICIDADES ${ }^{*}$
}

\author{
Vivian Colella Esteves \\ Isabela Brunini Simões Padula
}

Realizado no Recife, em novembro de 2019, o IV Seminário Internacional Desfazendo Gênero teve como temática central as dissidências e resistências de uma infinidade de corpos possíveis. Nossas pesquisas foram apresentadas a partir de um trabalho que pretendeu discutir o impacto das relações de gênero, raça, classe e idade na experiência das crianças na Educação Infantil. As discussões proporcionadas a partir da apresentação, somadas às contribuições trazidas pelas mesas de debate, nos possibilitaram pensar os corpos infantis e suas experiências nos espaços de educação a partir de diferentes perspectivas.

Neste sentido, é preciso pensar antes a trajetória do conceito de infância ao longo da história, pois os significados atribuídos à infância interferem diretamente na construção de um "corpo infantil". Ariès (1981), no clássico História social da família e da criança, aponta para o fato de a sociedade medieval francesa praticamente ignorar, antes do século XIII, a ideia de "infância", sendo especialmente após a Reforma Protestante que a criança passa a ser entendida como frágil e angelical nesse contexto (ARIÈS, 1981).

No que diz respeito aos estudos das infâncias, a Psicologia do Desenvolvimento foi, e ainda é, uma vertente popular na área, apesar de analisar as experiências de bebês e crianças a partir de referenciais adultocêntricos como andar e falar, desviando nosso olhar de diversas outras linguagens usadas pelas crianças. Segundo Patrícia Dias Prado:

Dentro de uma das perspectivas em Psicologia, há uma criança fragmentada em tantas áreas de desenvolvimento: cognitivo, so-

*DOI - 10.29388/978-65-86678-02-4-0-f.93-106 
cial, afetivo, linguístico, sensorial, motor, constituída ainda por um conjunto de comportamentos que, reunidos por articulações teóricas abstratas, desvincula-a do âmbito social como alguém impermeável às relações de classe, de gênero, de etnia alguém que está apenas em processo de socialização e, portanto, numa trajetória de capacitação para a vida social, adulta e produtiva (1999, p. 111).

No âmbito da Sociologia da Infância, trabalhos produzidos durante a década de 1990 passam a considerar as crianças como atrizes sociais e produtoras de cultura. Os estudos sociológicos, até então, mantinham as crianças em posição de inércia, no que diz respeito à socialização, entendendo que atuavam como intermediárias passivas nos processos de absorção de valores da sociedade adulta, pressuposto teórico atravessado por fundamentos durkheimianos. A partir, sobretudo, da década de 1980, diversos intelectuais, dentre eles Jean Qvortrup, William Corsaro e Prout, passam a produzir pesquisas que vão na contramão dessas ideias, concebendo a criança "[...] como sujeito e ator social do seu processo de socialização, e também construtores de sua infância" (ABRAMOWICZ; OLIVEIRA, 2010, p. 42).

É preciso ressaltar ainda a importância dos movimentos sociais da década de 1980 no Brasil, liderados, principalmente, por mulheres (TELES; SANTIAGO; FARIA, 2018), as quais reivindicavam direitos políticos e sociais para as crianças, e que trouxeram “[...] para a luta a crítica ao papel tradicional da mulher na família e a defesa da responsabilidade de toda a sociedade em relação à educação das novas gera ções" (FINCO; GOBBI; FARIA, 2015, p. 9). Traçar os percursos percorridos pelo conceito de "infância" no tempo e no espaço, no âmbito acadêmico e político, é importante para entender seu caráter social e localizado, resultado de aspectos culturais e históricos que permanecem sempre em transformação.

Além dos diferentes significados atribuídos à ideia de infância, é importante olhar para a construção da ideia de "corpo" no tempo e no espaço. Ambos os conceitos, corpo e infância, estiveram em disputas entre diferentes atores: Igreja, Medicina, Biologia, Psicologia, den- 
tre outros. Um exemplo de como esse 'corpo' pode ser visto de muitas formas e lugares diferentes é a visão da Igreja trazida por Nicole Pellegrin (2008), no Volume 1, da História do Corpo:

Num mundo impregnado de religiosidade cristã, o corpo não é, para $\left(\right.$ quase $^{\star}$ ) todos, senão o habitat temporário de uma alma imortal. Tristemente sexuado, verminado para sempre, votado à corrupção e encerrando em si esta alma, o corpo não pode - na melhor das hipóteses - passar de um instrumento a serviço da salvação, salvação pessoal e salvação comunitária que se confundem. Não obstante, porque ele ressuscitará e porque é também a imagem de Deus que escolheu fazer dele a experiência na sua própria vida humana, este corpo de ser respeitado em vista dos fins últimos (p. 133).

Historicamente, a Igreja continuamente foi uma das maiores reguladoras do corpo, impondo normas sociais baseadas na religião, ditando regras baseadas na moral, separando os corpos puros dos corpos pecaminosos. Segundo Matthews-Grieco (2008), na história da Europa Ocidental o corpo aparece sob dois aspectos:

Primeiramente, sob o aspecto do costume e da legislação: tanto um como a outra buscam disciplinar e dirigir suas funções reprodutivas, reprimindo os impulsos desordenados da sexualidade por razões que participam ao mesmo tempo do social e do espiritual. Em segundo lugar, o corpo aparece como o agente (ou a vítima) de atos sexuais transgressivos e, portanto, como lugar privilegiado de "crimes" contra a religião, a moral e a sociedade: ele testemunha assim a eterna e relativa impotência das restrições sociais que visam conter as práticas sexuais dentro dos limites estabelecidos pelas convenções e pelas leis (p. 2017).

Esse controle dos corpos foi marcado por outros diferentes "dispositivos sexopolíticos" (PRECIADO, 2011, p. 14) ao longo do tempo: pelo advento do casamento, no século XV; pelos esforços da Europa Ocidental, no século XVII, em “desenvolver uma visão do cor- 
po e de sua sexualidade que fosse compatível com a ordem social, o respeito pela religião e o crescimento da população" (MATTHEWSGRIECO, 2008, p. 2018); e pelo olhar médico, a partir do século XIX, em que a sexualidade estava sendo debatida principalmente sob este viés, e quando "A escuta terapêutica substitui a confissão: o anormal, o abjeto o transtornado, a aberração da natureza e o psicótico substituem o fraudulento e o pecaminoso" (BENTO, 2006, p. 111). Preciado (2011) reforça o papel da Medicina, até os dias atuais, na regulação normativa dos corpos:

O Império dos Normais, desde os anos 1950, depende da produção e da circulação em grande velocidade do fluxo de silicone, fluxo de hormônio, fluxo textual, fluxo das representações, fluxo de técnicas cirúrgicas, definitivamente, fluxo dos gêneros. Com certeza, nem tudo circula de maneira constante e, sobretudo, os corpos não retiram os mesmos benefícios dessa circulação: é nessa circulação diferencial de fluxos de sexualização que se desempenha a normalização contemporânea do corpo ( $\mathrm{p}$. 13).

Outra instituição que historicamente caminhou junto com a Igreja, e contribuiu para a reprodução de práticas sociais baseadas na moral e na religião, foi a escola. Durante a história da educação, o controle dos corpos, preocupado em “[...] vigiar, controlar, modelar, corrigir, construir os corpos de meninos e meninas, de jovens homens e mulheres" (LOURO, 2000, p. 60), sempre fez parte das práticas e estratégias pedagógicas:

Um corpo escolarizado é capaz de ficar sentado por muitas horas e tem, provavelmente, a habilidade para expressar gestos ou comportamentos indicativos de interesse e de atenção, mesmo que falsos. Um corpo disciplinado pela escola é treinado no silêncio e num determinado modelo de fala; concebe e usa o tempo e o espaço de uma forma particular (LOURO, 2007, p. 21). 
Esse processo de escolarização do corpo, que engessa as práticas, disciplina e avalia os corpos e reproduz estereótipos binários, é parte de uma Pedagogia da sexualidade. Os espaços educativos tentam distanciar-se de uma educação sexual pautada na laicidade e no respeito às diferenças, para exercer uma suposta "dessexualização do espaço escolar" (LOURO, 2007). Porém, o espaço físico (banheiro dividido entre meninos e meninas), as práticas pedagógicas e as disciplinas segmentadas (Educação Física dividida entre meninos e meninas, a velha dicotomia entre rosa e azul), as regras, as normas de conduta e o uniforme (também dividido entre meninos e meninas), não se estabelecem como formas de normatizar os corpos, constituindo, portanto, uma educação sexual velada?

Além disso, a estratégia de controle dos corpos não afeta apenas as crianças, mas também as/os docentes. Sara Wagner (2019), durante fala na mesa redonda do Seminário Desfazendo Gênero, compartilhou com o público o fato de, enquanto professora e travesti, ter suas aulas sempre vigiadas pela gestão escolar. Maciel também apresenta, a partir de sua pesquisa de relatos autobiográficos de professoras lésbicas, situações nas quais essas docentes, por seus corpos e desejos sexuais, vivenciaram momentos constrangedores no cotidiano escolar, o que não as manteve, por outro lado, paralisadas, mas produzindo “[...] modos de sobrevivência e resistência ativa nos contextos escolares" (MACIEL; GARCIA, 2014, p. 170).

Assim, o esforço contínuo da sociedade pela adaptação dos corpos a partir de referenciais binários de normalidade marca a vida dos sujeitos desde o nascimento, e pode ser visualizada nas vivências das crianças intersex, marcadas, sobretudo, pela interferência médica. Paula Sandrine Machado (2005), em O sexo dos anjos: um olhar sobre a anatomia e a produção do sexo (como se fosse) natural, propõe um debate neste sentido. $\mathrm{O}$ argumento principal da pesquisadora reside no estabelecimento do sexo e do gênero como uma construção cultural, dinamizando a relação entre natureza e cultura. Segundo ela, definir natureza a partir de normas sociais, especialmente as dicotômicas, enfraquece esta condição, que já foi contestada na análise de socieda- 
des nas quais sexo não é concebido binariamente. É o caso das crianças nascidas intersex em hospitais do Rio Grande do Sul, por ela analisado. A percepção da anatomia dessas crianças em um viés de sexo dicotômico indica, para a autora, que "[...] o sexo é, desde sempre, marcado pelo gênero" (MACHADO, 2005, p. 254). Os médicos e familiares, atores sociais diretamente envolvidos na caracterização dessas crianças, têm seus olhares marcados pela estrutura de gênero dicotômica, refletindo diretamente nas decisões que tomam quanto ao destino das crianças intersex. Estas são submetidas a cirurgias de "[...] correção" de sexo, visando adaptar os corpos às normas sociais, "[...] realinhar o corpo com a natureza de um sexo que já o habita" (MACHADO, 2005, p. 263) Mas como poderia o sexo ser natural se é a própria intervenção médica que o cria? Ainda que a anatomia das crianças varie, seus corpos serão negociados e o esforço médico atuará para adaptar aquele corpo às categorias binárias de gênero (e à heteronormatividade, já que a possibilidade de penetração é levada em conta). Assim, quando a coerência entre o sexo essencial (em uma estrutura binária) e as aparências é colocada em perigo, as famílias não admitem e buscam diferentes soluções, sempre tentando realinhar as crianças a seus devidos papéis, em um sistema dicotômico de gênero e sexo, "[...] restando pouca tolerância para a indefinição e a ambiguidade" (MACHADO, 2005, p. 261).

Para além da dicotomia masculino/feminino baseada em uma suposta diferença essencial entre sexos, todos esses dispositivos de disciplinamento dos corpos buscam igualmente insistir na heterossexualidade compulsória. Preciado (2011), ao realizar uma leitura conjunta de Foucault e Witting, aponta para a heterossexualidade como "[...] tecnologia biopolítica, destinada a produzir corpos straight” (p. 12). Para garantir esta heterossexualidade, as crianças, desde o nascimento, têm seus comportamentos vigiados e julgados, a partir de códigos sociais ditos femininos ou masculinos:

E, como as práticas sexuais se dão na esfera do privado, será através do gênero que se tentará controlar e produzir a heteros- 
sexualidade. Se meninos gostam de brincar de boneca ou meninas odeiam brincar de casinha, logo terá um olhar atento para alertar aos pais que seu/sua filho/a tem comportamentos "estranhos" (BENTO, 2011, p. 552).

A escola é uma das principais instâncias a manter grandes esforços no sentido de assegurar a heterossexualidade. A Educação Infantil, apesar de constituir um espaço no qual à criança é permitido brincar, em contraposição ao processo de escolarização tradicionalista que posteriormente precisarão enfrentar, também pode funcionar como espaço de controle e disciplina, criando desigualdades múltiplas e simultâneas e impactando as experiências das crianças.

Daniela Finco (2010), ao pesquisar a educação de meninas e meninos que transgrediam os estereótipos de gênero, verificou que algumas características tidas como naturalmente femininas ou masculinas derivavam, na realidade, de esforços contínuos de adultos, na tentativa de marcar e disciplinar os corpos e as habilidades dessas crianças. Para além da diferenciação no que diz respeito aos comportamentos infantis - quando meninas eram descritas pelas professoras como meigas e caprichosas, e os meninos como descuidados e agitados -, também os brinquedos e as brincadeiras eram controlados a partir de um modelo binário de gênero. Finco mostra, então, que as crianças são levadas a desenvolver suas potencialidades de acordo com modelos pré-definidos de feminilidade e masculinidade, o que não impede que algumas delas rejeitem esse padrão e resistam às expectativas adultas, sendo, no entanto, silenciadas e marginalizadas.

Impossível não problematizar o fato dos corpos infantis, assim como outros corpos, não serem marcados pela sociedade apenas a partir de referenciais de sexo e gênero, mas também de raça e classe. É o caso do estudo de Oliveira (2010), que revela, a partir do trabalho de campo em uma creche, a diferenciação no tratamento dado a crianças negras e brancas, entre 0-3 anos, apesar do discurso sistemático das professoras que diziam trabalhar a partir da ideia de que "todos são iguais". Segundo a pesquisadora, as crianças negras estavam, na maior 
parte do tempo, fora de práticas de carinho diferenciadas que as docentes aplicavam às crianças brancas, como, por exemplo, ganhar o colo da professora e receber beijos ao chegar à creche. Situações semelhantes aconteceram durante a pesquisa de Farias (2016) que, a partir da análise de desenhos das crianças, percebeu que os cabelos desenhados eram sempre lisos e as peles sempre pintadas com o "lápis cor da pele" (de cor salmão, que representa peles claras), inclusive por crianças negras, salvo algumas exceções. Brincar "de chapinha que deixa o cabelo loiro e liso" (p. 100) era hábito frequente das meninas.

Além da Igreja, Medicina e escola, outras instâncias também trabalham como dispositivos de regularização e controle dos corpos. Como lembrou Guacira Lopes Louro (2008), na contemporaneidade, esses dispositivos se multiplicam: publicidade, internet, cinema, televisão; um aparato bélico de grandes proporções que hierarquiza e classifica os corpos. Desta forma, ao definir um modelo de corpo ideal a ser sistematicamente reafirmado e garantido por diferentes instâncias sociais (homem, branco, cis, heterossexual, adulto), criam-se, por outro lado, corpos ditos anormais, estranhos e invisíveis. No Brasil, grupos políticos em posição de poder, guiados por ideais que passam longe da laicidade e contam com grande apoio de parte da sociedade civil, têm empreendido esforços na tentativa de barrar a educação sexual nas escolas, argumentando que esta pode destruir uma suposta "inocência das crianças", essencialmente puras e angelicais. A pergunta que fazemos é: quem são essas crianças? Quais são os corpos infantis tidos como dóceis e angelicais? Certamente não os das milhares de crianças que vivem em situação de rua no país; nem os de meninos negros e pobres sistematicamente reprovados no sistema público de ensino ${ }^{1}$; tão menos o de Alex, aos 8 anos, agredido pelo pai até a morte, por gostar de brincar de dançar e rebolar ${ }^{2}$. A mesma multidão que reivin-

\footnotetext{
${ }^{1}$ CARVALHO, M. P. de. Sucesso e fracasso escolar: uma questão de gênero. $E d u$ cação e Pesquisa, São Paulo, v. 29, n. 1, p., 185-193, jan/jun 2003. Disponível em: https://doi.org/10.1590/S1517-97022003000100013>. Acesso em: 06 fev. 2020.

${ }^{2}$ Disponível em: < http://g1.globo.com/rio-de-janeiro/noticia/2014/12/homem-quematou-filho-no-rio-por-ser-afeminado-vai-juri-popular.html $>$. Acesso em: 06 fev. 2020.
} 
dica a inocência das crianças é aquela que brada pela diminuição da maioridade penal.

No entanto, "os corpos não se conformam, nunca, completamente, às normas pelas quais sua materialização é imposta" (BUTLER, 1999 , p. 154), questionando as regras hegemônicas e criando uma outra face de resistência e ação:

Já não se trata apenas, de campos teóricos ou instituições sociais tradicionais disputando a primazia para delimitar os saberes pertinentes e as práticas adequadas ou legítimas; ao seu lado, geralmente como contraponto e oposição, expressam-se novos movimentos sociais, liderados por feministas e por "minorias" sexuais, com outras concepções, novos discursos e outra ética (LOURO, 2000, p. 64).

As crianças, nesse movimento, também resistem, por meio não apenas da fala verbalizada (já que muitas ainda não o fazem), mas de choros, mordidas, gritos, dentre outras linguagens assumidas pelas crianças. Evidente que as crianças, em seu lugar de subalternidade em um mundo adulto, flexionam as fronteiras entre submissão e agência, significando e ressignificando as informações às quais estão expostas. Suas formas de expressão, constantemente silenciadas e relevadas por serem "inúteis" (a não ser que estejam localizadas no ideal de desenvolvimento adultocêntrico), desnaturalizam aspectos tidos como essenciais e borram as fronteiras e sentidos que o mundo adulto rigidamente estabeleceu, podendo encontrar, também na creche, em pré-escolas e escolas, ambientes frutíferos de expressão, pois representam importantes espaços de socialização para as crianças longe do âmbito familiar, possuindo aspectos disciplinares, mas também transgressores:

A escola não é uma ilha. Embora saibamos que historicamente tem cumprido principalmente o papel de reprodutora de uma visão naturalizada das relações sociais, notamos que os debates que atravessam a sociedade brasileira também podem se sentir nas salas de aula. Há um saudável incômodo de educadores/as, 
gestores/as das políticas públicas e do ativismo em trazer para o cotidiano escolar a reflexão dos direitos humanos em uma perspectiva ampla. Está em curso, portanto, a produção incessante de contradiscursos, e a escola, de múltiplas formas, está inserida nessa disputa (BENTO, 2011, p. 558).

Durante o Seminário Desfazendo Gênero, uma das reflexões oriundas dos debates e da apresentação de nossas pesquisas diz respeito à Pedagogia Queer, como estratégia de resistência e questionamento. Segundo Gracia Trujillo Barbadillo (2019), durante fala em uma Mesa Redonda do Seminário, a Pedagogia Queer, apesar das críticas acerca de ser oriunda de teoria importada dos EUA e restrita ao meio acadêmico, constitui-se como uma ferramenta potente para interpretar o mundo de forma crítica. A Pedagogia Queer questiona os discursos abstratos da diversidade, afirma a não neutralidade dos corpos, problematiza categorias fixas, a noção de normalidade e seus binarismos. Assim, "Pensar queer significa questionar, problematizar, contestar, todas as formas bem-comportadas de conhecimento e de identidade" (SILVA, 2004, p. 107). Afinal, como questionou Paul B. Preciado (2013), quem defende a criança queer?

Quem defende o direito das crianças diferentes? Os direitos do menino que adora se vestir de rosa? Da menina que sonha em se casar com a sua melhor amiga? Os direitos da criança queer, bicha, sapatão, transexual ou transgênero? Quem defende o direito da criança a mudar de gênero, se for da vontade dela? Os direitos das crianças à livre autodeterminação de gênero e de sexualidade? Quem defende os direitos da criança a crescer num mundo sem violência sexual ou de gênero? (p. 97)

Contudo, a Pedagogia Queer não é direcionada somente “(...) àqueles ou àquelas que se reconhecem nessa posição-de-sujeito, isto é, como sujeitos queer" (LOURO, 2001, p. 552). A Pedagogia Queer fala pela multiplicidade, pensá-la é pensar também pedagogias descolonizadoras; pedagogias críticas; práticas não normativas; a transgressão dos binarismos homem/mulher, feminino/masculino, heterossexual/ 
homossexual; é levar em conta as fronteiras e a fluidez das fronteiras; a Pedagogia Queer é descentralizadora, é, enfim, a pedagogia dos conflitos e questionamentos:

Uma pedagogia e um currículo queer se distinguiriam de programas multiculturais bem intencionados, onde as diferenças (de gênero, sexuais ou étnicas) são toleradas ou são apreciadas como curiosidades exóticas. Uma pedagogia e um currículo queer estariam voltados para o processo de produção das diferenças e trabalhariam, centralmente, com a instabilidade e a precariedade de todas as identidades. Ao colocar em discussão as formas como o 'outro' é constituído, levariam a questionar as estreitas relações do eu com o outro. A diferença deixaria de estar lá fora, do outro lado, alheia ao sujeito, e seria compreendida como indispensável para a existência do próprio sujeito: ela estaria dentro, integrando e constituindo o eu. A diferença deixaria de estar ausente para estar presente: fazendo sentido, assombrando e desestabilizando o sujeito. Ao se dirigir para os processos que produzem as diferenças, o currículo passaria a exigir que se prestasse atenção ao jogo político aí implicado: em vez de meramente contemplar uma sociedade plural, seria imprescindível dar-se conta das disputas, dos conflitos e das negociações constitutivos das posições que os sujeitos ocupam (LOURO, 2001, p. 550).

\section{Referências}

ABRAMOWICZ, Anete; DE OLIVEIRA, Fabiana. A sociologia da infância no Brasil: uma área em construção. Educação (UFSM), Santa Maria, v. 1, n. 1, p. 39-52, 2010.

ARIÈS, Philippe. História social da família e da criança. Rio de Janeiro: Guanabara, 1981.

BARBADILLO, Gracia Trujillo. Conferência de abertura: Pedagogías queer para tiempos de combate, Pernambuco, 2019. Conferência de abertura do: IV SEMINÁRIO INTERNACIONAL DESFAZENDO 
GÊNERO: CORPOS DISSIDENTES, CORPOS RESISTENTES: DO CAOS À LAMA, 2019, Pernambuco Anais..., Pernambuco, 2019.

BENTO, Berenice. Corpo e História. In: A Reinvenção do

Corpo: sexualidade e gênero na experiência transexual. RJ: Garamond, 2006. p. 109-132.

. Na escola se aprende que a diferença faz a diferença. Estudos Feministas, Florianópolis, v. 19, n. 2: p. 336, 2011.

BUTLER, Judith. Corpos que pesam: sobre os limites discursivos do 'sexo'. In: LOURO, Guacira Lopes (Org.). O corpo educado: pedagogias da sexualidade. Belo Horizonte: Autêntica, 1999. p. 151-172.

CARVALHO, Marília Pinto de. Sucesso e fracasso escolar: uma questão de gênero. Educação e Pesquisa, São Paulo, v. 29, n. 1, p. 185-193, jan/jun, 2003.

CÉSAR, M. R. d. A. (2012). A diferença no currículo ou intervenções para uma pedagogia queer. ETD - Educação Temática Digital, Campinas, v. 14, $\mathrm{n}^{\circ}$ 1, p. 351-362. jan./jun., 2012. Disponível em: < $\underline{\text { https:// }}$ nbn-resolving.org/urn:nbn:de:0168-ssoar-313134>. Acesso em: 29 jan. 2020.

FARIAS, Ana Carolina Batista de Almeida. Loira você fica muito mais bonita: relações entre crianças de uma EMEI da cidade de São Paulo e as representações étnico-raciais em seus desenhos. Universidade de São Paulo, 2016. Tese de Doutorado - Faculdade de Educação, Universidade de São Paulo, São Paulo, 2016.

\section{FINCO, Daniela. Educação Infantil, espaços de confronto e convívio}

com as diferenças: análise das interações entre professoras e meninas e meninos que transgridem as fronteiras de gênero. São Paulo, Universidade de São Paulo, 2010. Tese (Doutorado em Educação) - Faculdade de Educação da Universidade de São Paulo, São Paulo - SP, 2010.

FINCO, Daniela; GOBBI, Marcia Aparecida; FARIA, Ana Lúcia Goulart de (orgs). Creche e feminismo: desafios atuais para uma educação descolonizadora. Campinas, SP: Edições Leitura Crítica; Associação de 
Leitura do Brasil - ALB; São Paulo: Fundação Carlos Chagas - FCC, 2015.

LOURO, Guacira Lopes. Corpo, escola e identidade. Educação \& Realidade, Porto Alegre, v. 25, n. 2, 2000.

. Gênero e sexualidade: pedagogias contemporâneas. Pro-Posições, Campinas, v. 19, n. 2 (56), p. 17 - 23, maio/ago. 2008.

. Pedagogias da Sexualidade. In: O corpo educado: pedagogias da sexualidade. 2. ed. Belo Horizonte: Autêntica, 2007. p. 07 -34 .

. Teoria queer: uma política pós-identitária para a educação.

Revista Estudos Feministas, Florianópolis, v. 9, n. 2, p. 541-553, 2001.

MACHADO, Paula Sandrine. O sexo dos anjos: um olhar sobre a anatomia e a produção do sexo (como se fosse) natural. Cadernos Pagu, Campinas, n. 24, p. 249-281, 2005.

MACIEL, Patrícia Daniela; GARCIA, Maria Manuela Alves. Os femininos no magistério: professoras lésbicas nas escolas. Currículo sem Fronteiras, v. 14, n. 3, p. 160-180, 2014.

MATTHEWS-GRIECO, Sara F. Corpo e sexualidade na Europa do antigo regime. In: CORBIN, A.; COURTINE, J.; VIGARELLO, G. História do Corpo. Tradução de Lúcia M. E. Orth. Da renascença às luzes. Petrópolis, RJ: Vozes, 2008. p. 217 - 301.

OLIVEIRA, Fabiana de; ABRAMOWICZ, Anete. Infância, raça e paparicação. Educação em revista, Belo Horizonte, v. 26, n. 2, 2010.

PELLEGRIN, Nicole. Corpo do comum, usos comuns do corpo. In: CORBIN, A., COURTINE, J.; VIGARELLO, G. Tradução de Lúcia M. E. Orth. História do Corpo. V. 1: Da renascença às luzes. Petrópolis, RJ: Vozes, p. 131-216, 2008.

PRADO, Patrícia Dias. As crianças pequenininhas produzem cultura? Considerações sobre educação e cultura infantil em creche. Pro-Posições, Campinas, v. 10, n. 1, p. 110-118, 1999. 
PRECIADO, Paul B.. Multidões queer: notas para uma política dos "anormais". Revista Estudos Feministas, Florianópolis, v. 19, n. 1, p. 11-20, 2011.

. Quem defende a criança Queer? Jangada. Viçosa, Minas Gerais, $\mathrm{n}^{\circ} 1$, p. 99-99, 2013. Disponível em<https://www.revistajangada.ufv.br/Jangada/article/view/17/2 >. Acesso em: 28 jan. 2020.

SILVA, Tomas Tadeu da. Uma coisa "estranha" no currículo: a teoria queer. In: . Documentos de identidade: uma introdução às teorias do currículo. 3. ed. Belo Horizonte: Autêntica, 2013. p. 105-109. TELES, Maria Amélia; SANTIAGO, Flavio; FARIA, Ana Lúcia Goulart de. Por que a creche é uma luta das mulheres? Inquietações femininas já demonstram que as crianças pequenas são de responsabilidade de toda a sociedade. São Carlos: Pedro \& João Editores, 2018. 295 p. YORK, Sara Wagner. Mesa redonda: Decolonialidades em estudos sobre gênero e sexualidade: por um pensamento dissidente. Pernambuco, 2019. IV SEMINÁRIO INTERNACIONAL DESFAZENDO GÊNERO: CORPOS DISSIDENTES, CORPOS RESISTENTES: DO CAOS À LAMA, 2019, Pernambuco, Anais..., Pernambuco, 2019. 